
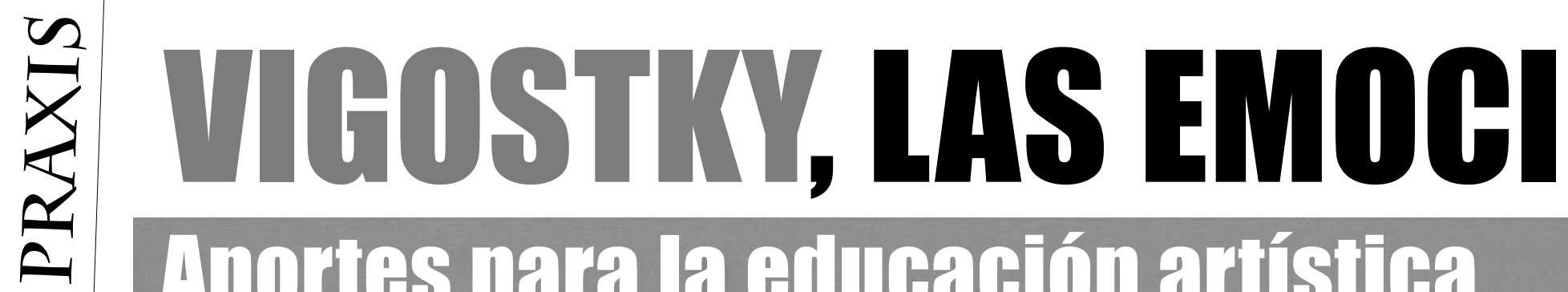

Ajorios para la gilubación artístioa

Petaco y medio.

Obra del artista Leon Jainer.

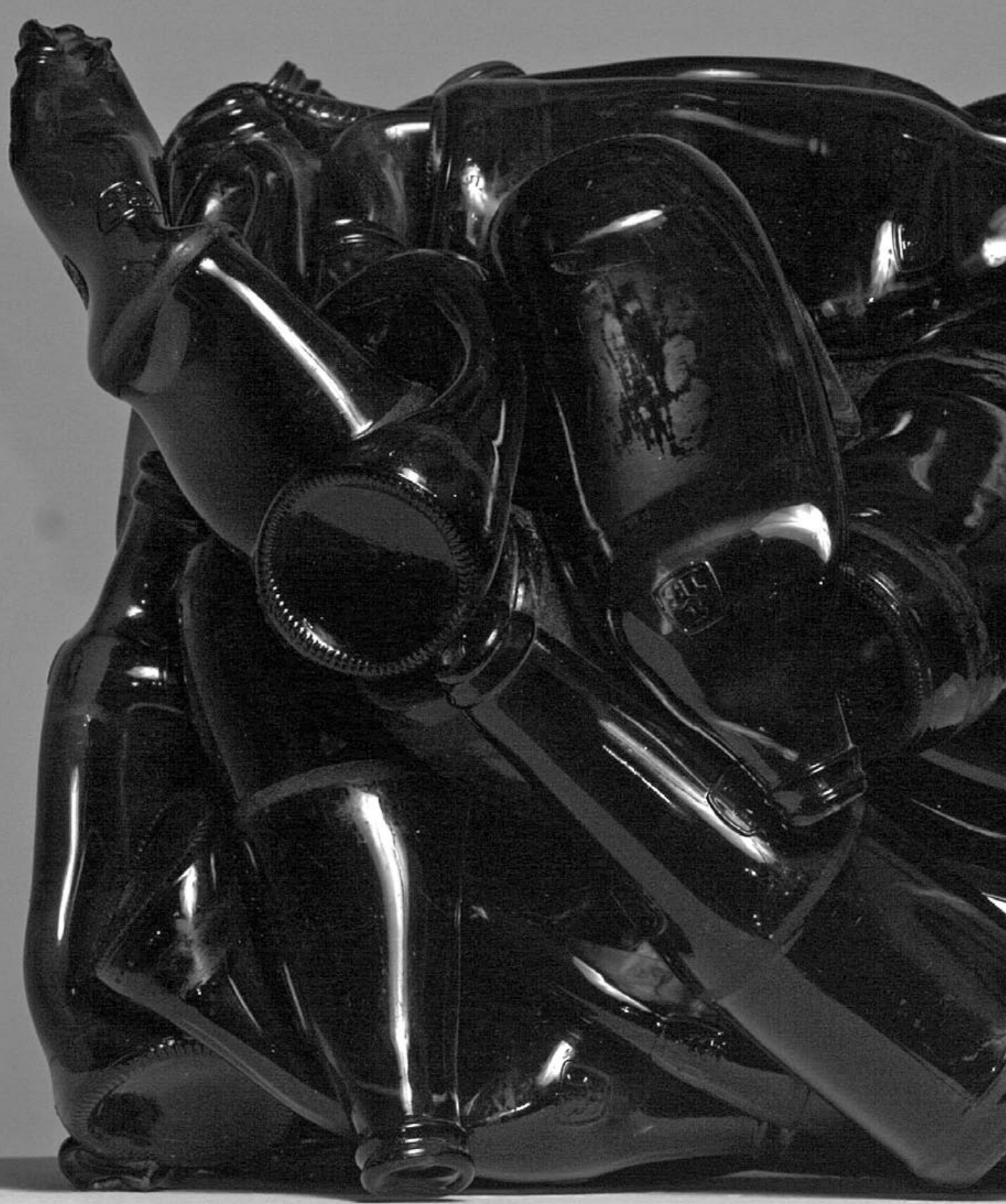




\section{DNES Y EL ARTE}

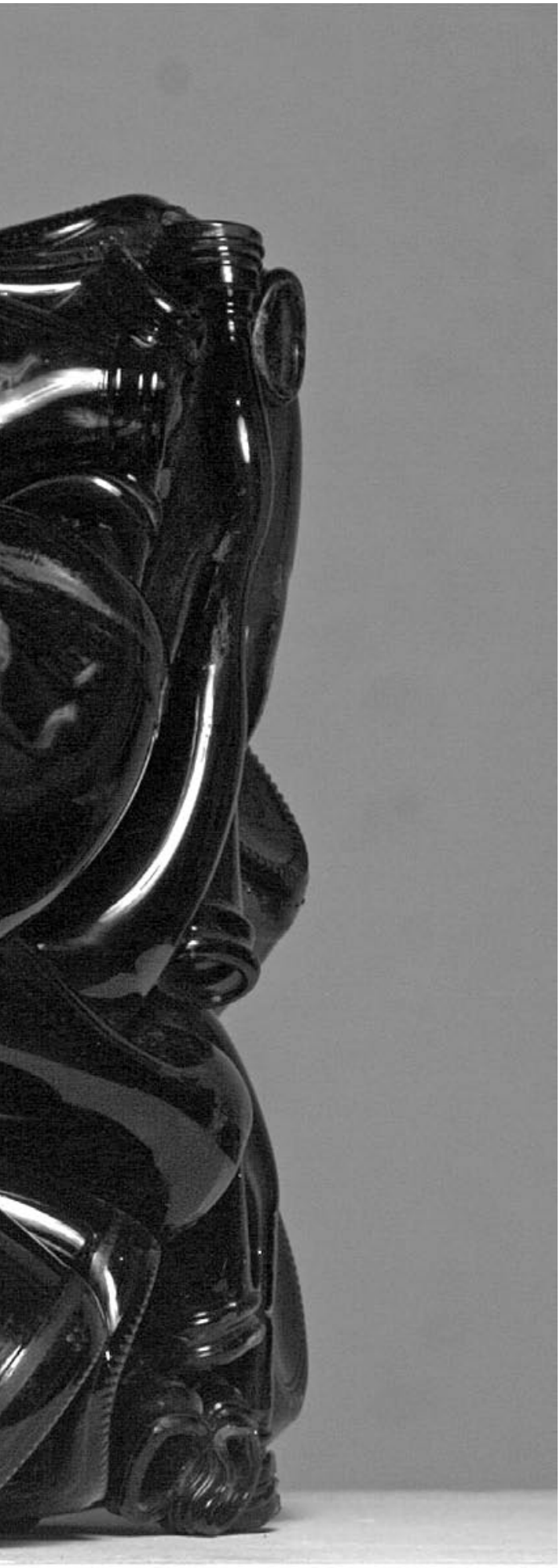

JULIA MARGARITA BARCO

jmbarco@uniminuto.edu

Maestra en Artes Plásticas, Especialista en Educación y Desarrollo Cultural, Magíster en Educación. Desde el año 2001 coordina la Licenciatura en Educación Básica con énfasis en Educación Artística de Uniminuto.

\section{R E S U M E N}

Este artículo se propone un reconocimiento al pensamiento visionario de Vigostky y su aporte a la comprensión y fortalecimiento de la Educación Artística. Se destacan sus pronunciamientos con relación al arte como educador de las emociones desde una visión holística, y asimismo, sobre el desarrollo de la imaginación, su cristalización en la creatividad y la expresión artística como actividades que integran pensamiento y emoción.

Por su muerte temprana, y otros asuntos de orden político, los aportes de este pensador no se conocieron suficientemente. Al confrontar muchos de sus pronunciamientos con las comprensiones actuales de la psicología cognitiva, a favor del papel formativo del arte como operación de construcción de símbolos y por tanto como forma de conocimiento interpretativo donde operan intuición y razón, es cuando la obra del gran pensador resulta más actual que nunca.

Palabras clave: experiencia artística, emociones, imaginación, creatividad.

\section{A B S T R A C T}

This article acknowledges Vytgostki's visionary thinking as a contribution to the comprehension and strengthening of the artistic education. It highlights Vytgostki's considerations on how art can be viewed as an emotional educator from a holistic approach as well as his observations on the development of imagination, his influence on creativity and on artistic expression as activities that integrate emotion and thinking. Due to his early death and other political issues at the time, the brilliance of this man was poorly recognized. Many of his considerations support the formational role of art as a means for the construction of symbols, and therefore as a means of interpretative knowledge where intuition and reason work together. When contrasting these considerations to the contemporary understandings of Cognitive Psychology, the work of this man is more contemporary than ever.

Key words: artistic experience, emotions, imagination, creativity. 


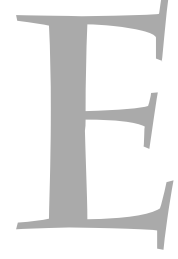

n la actualidad son considerables los avances de las ciencias cognitivas en la comprensión de los procesos mentales que explican el pensamiento humano y el acto de conocer, aunque en el campo de las emociones, quizá por su complejidad, este progreso ha sido más restringido. Son de mencionar trabajos como los de Elster (2001) y Evans (2002), los cuales se han ocupado de la comprensión y naturaleza de las emociones y su clasificación en básicas y cognoscitivas superiores. También desde la neurobiología se han intentado aproximaciones para encontrar explicaciones a fenómenos tan sutiles como son las emociones sociales. ${ }^{1}$

Ya hacia mediados del siglo XX se hacen visibles algunos esfuerzos en el estudio de las emociones, en cabeza de los psicólogos desarrollistas: Jean Piaget y Lev Vigostky. Las aportaciones de este último hoy están más vigentes que nunca y se consideran de gran agudeza para quienes estamos abocados al ejercicio de la enseñanza del arte, aunque no se le haya reconocido con suficiente justeza en los estudios recientes sobre la Educación Artística. A ello nos referimos en este artículo.

En el estudio de Jean Piaget (1954) Las relaciones entre inteligencia y afectividad dentro del desarrollo del niño se aprecian comprensiones sorprendentes acerca de la indisoluble relación entre inteligencia y emoción, entre conocer y desear. Para tal propósito el autor se refiere, de manera particular, a la conformación de los sentimientos morales y la voluntad, los cuales se desarrollan en el niño paralelamente a las estructuras mentales y a partir de su acción con el mundo.

Sin embargo, es en la obra de Vigostky en donde es posible encontrar planteamientos más concretos acerca de las relaciones entre el arte y las emociones: el arte como actividad medular de la existencia humana, su relación con la imaginación y la creatividad explicadas como procesos psicológicos superiores, y por lo tanto, su caracterización como actividad que involucra la conciencia en cuanto posibilita el distanciamiento capaz de integrar, de manera holística, las emociones y el pensamiento en la experiencia expresiva e interpretativa, y en interacción con la cultura para otorgar sentidos.

En la Psicología Pedagógica, Vigostky (2001) se refiere a la educación de la conducta emocional, para lo cual intenta primeramente una explicación de la naturaleza biológica de las emociones. Estas son concebidas como emociones primarias instintivas que cumplieron el papel de posibilitar la adaptación en términos de supervivencia. Hoy, nuestras emociones se entienden como "formas atenuadas" de estos instintos que se han ido atrofiando por su inutilidad. Quizá por ello el aspecto emocional no ha ocupado un papel central en la educación al lado de las demás formas de desarrollo de la conducta. Es así como las metodologías del maestro y los reglamentos convivenciales de las instituciones educativas tienden más a reprimir que a educar las emociones, a partir de su reconocimiento.

Para Vigostky, esta comprensión es profundamente equivocada y por ello se propone enseguida considerar la naturaleza psicológica de las emociones, presente en todas las actuaciones del hombre y visible en el tinte particular que les imprime. Caracterizada la conducta como el resultado de la interacción del organismo con el ambiente ${ }^{2}$, lo esperable sería atender a la educación de las emociones para lograr un equilibrio que dé cuenta de la conciencia y manejo de las mismas.

En este orden de ideas, la comprensión y canalización de las emociones cobra especial importancia en la educación de los niños, dependiendo de la adecuada utilización de estímulos y de la organización del medio, así como de las posibilidades de hacerlas conscientes para reeducarlas en la interacción social ${ }^{3}$. Las emociones son capaces de influir la conducta mejor que ningún otro modo, siempre que sean capaces de dejar huella. De lo que se trata, entonces, es de pensar en actividades con contenidos sugerentes, capaces de motivar suficientemente y de afectar al estudiante ${ }^{4}$, 
todo lo cual ha de tenerse en cuenta en el proceso educativo.

Todo conocimiento debe sugerir una actitud viva, de asombro ante el mundo y también de avidez por su profundización. iHe ahí el secreto y el sentido del aprendizaje!

Con gran satisfacción se puede apreciar aquí cómo Vigostky, el creador de los conceptos fundamentales de la psicología contemporánea, desde una aguda mirada de las emociones, está reafirmando muchas de las intuiciones que los maestros de arte hemos venido sosteniendo, apoyados en las prácticas educativas: la naturaleza integral del ser humano y por tanto la necesidad de concebir su desarrollo y aprendizaje en la articulación de sus dimensiones racional, ética y estética para que sea posible el diálogo entre pensamiento y sentimiento como indisolubles en una apropiación del mundo capaz de otorgar sentidos.

Todo ello me remitió a revisar La Imaginación y el Arte en la Infancia ${ }^{5}$, obra de la que había leído años atrás algunos de sus capítulos, quizá no los fundamentales, sin que en su momento surtiesen un efecto clarificador. Reafirmé, en primera instancia, cómo el aprendizaje es posible gracias a la plasticidad del cerebro y a complejos procesos mentales capaces de adaptarse a nuevas situaciones; también a la posibilidad de enfrentarse a experiencias significativas que dejen huella.

Comprendí que, además de su función reproductora, el cerebro es capaz de una asombrosa actividad combinatoria que logra mediante la reelaboración de experiencias pasadas a través de la imaginación, y cómo ésta es base de toda actividad creadora en la ciencia como en el arte y también en la vida cotidiana. La actividad imaginativa del ser humano es ya visible, desde temprana edad, en los juegos de los niños, cuyas vivencias elaboran creativamente. En este estudio sorprende cómo de manera visionaria Vigostky se anticipa a las recientes comprensiones de la cognición creativa ${ }^{6}$ acerca del fenómeno estructurante de la imaginación y su estrecha relación con el conocimiento previo y la formación de los conceptos. Contrariamente a lo que se piensa comúnmente, imaginación y realidad no son conceptos antitéticos. Según este autor su interrelación obedece a cuatro formas de interacción:

- La imaginación se apoya en la experiencia, por cuanto la fantasía extrae elementos de la realidad como en los cuentos y los mitos; por ello, la necesidad de ampliar el espectro de experiencias del niño para el fomento de su actividad creadora: "la actividad creadora de la imaginación se encuentra en relación directa con la riqueza y variedad de la experiencia acumulada por el hombre..." (p.16)

- La experiencia se apoya en la fantasía. Se trata de una combinación de segundo orden que construye y relaciona los productos de la fantasía con fenómenos complejos de la realidad; por ella se amplía la experiencia del ser humano, al ser capaz de imaginar lo que no ha visto, basándose en relatos de experiencias históricas o sociales, ajenas, que no ha experimentado personalmente.

- El enlace emocional. Todo sentimiento tiene, además de su manifestación externa, un equivalente interno en la selección de pensamientos, imágenes e impresiones. Un ejemplo de ello, la influencia de los colores en la vida anímica y su connotación simbólica en la representación de emociones. A la vez, esta relación es recíproca: la imaginación también influye en los sentimientos, como cuando experimentamos emociones de gozo o sufrimiento en la contemplación de una obra de teatro o inmersos en la lectura de un texto literario.

- La imaginación puede representar algo totalmente nuevo. Se trata de la imagen cristalizada convertida en objeto, posible a través de una compleja reelaboración de los elementos que entran en su composición. Así, sentimiento y pensamiento articulados en una combinación de necesidad y deseo mueven a la creación humana.

Esta última función de la imaginación podría explicar la necesidad del arte. Al igual que la invención técnica suple 
necesidades externas, se podría considerar que el arte responde a una necesidad de tipo interno. La creación artística posee una fuerza interior que le confiere una lógica interna, y en tanto atiende al mundo interior del hombre, a sentimientos y pensamientos que aluden al problema vital de la existencia, a las grandes preguntas, genera una conciencia social.

Para Vigostky (2000, pp. 31 y 36) La función imaginativa explica la creatividad: "Lo que llamamos creación no suele ser más que un catastrófico parto consecuencia de una larga gestación” y más adelante: “... depende de la capacidad combinativa ejercitada en esta actividad, de dar forma material a los frutos de la imaginación”.

Hoy cuando se habla de la creatividad en todos los ámbitos de la experiencia humana, reconociéndola como esencial en la sociedad actual, en donde lo único constante es el cambio, ésta reclama ser pensada seriamente desde la educación. Al respecto, Vigostky aporta una interesante claridad acerca del desarrollo de la imaginación, al refutar las creencias sobre la superioridad de la capacidad imaginativa del niño por encima de la del adulto, dado el cúmulo y complejidad de las experiencias con que cuenta el segundo para ejercer su capacidad combinatoria. Por esta razón, la imaginación requiere ser potenciada y desarrollada tempranamente, siempre que se proporcionen al niño los múltiples estímulos y materiales que favorezcan su fantasía. Es a partir de todo el material de la experiencia acumulada como se logran realizar disociaciones y nuevas agrupaciones de elementos esenciales para formar un todo con nuevo significado. Según el autor, la creatividad es también una función adaptativa en cuanto responde a necesidades y deseos que son el impulso de la creación: "Ningún descubrimiento o invención científica aparecen antes de que se creen las condiciones materiales y psicológicas necesarias para su surgimiento... por muy individual que parezca la creación, encierra siempre un coeficiente social."(Vigostky, 200o, p.38).

Estas comprensiones esenciales sobre la imaginación, como se comentó arriba, son presentadas en un sucinto estudio de los años treinta. Sus primeros cuatro capítulos ${ }^{7}$ contienen lo esencial de este trabajo, sobre los cuales Vigostky concluye reparando en la dialéctica de la creación, en la que los sentimientos

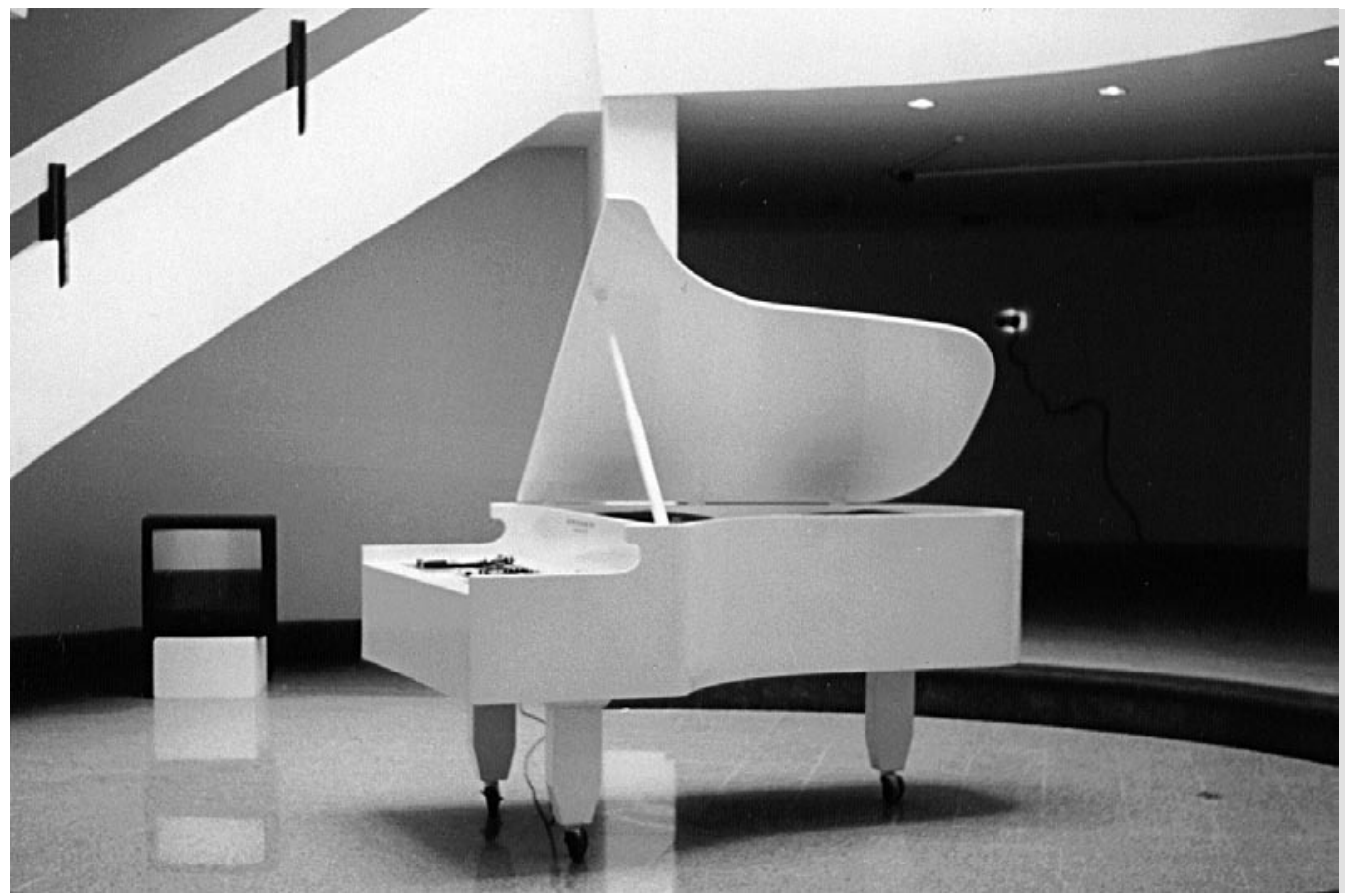

Obra de Joan Lear, 1999. 
de júbilo alternan con la desazón que produce su reto, al cual denomina "tortura". Para el autor, este fenómeno descubre el último y principal rasgo de la creación que encierra el círculo completo y dinámico del proceso creativo, el cual partiendo de la realidad ha de encarnarse nuevamente en ella.

El pensamiento de Vigostky frente al arte es recogido recientemente por Juan Jové Peres (2002), quien se refiere a las reflexiones encontradas en uno de su primeros libros, escrito hacia la década de los años veinte: La Psicología del arte (Vigostky, 1970). Sostiene cómo en uno de sus capítulos sobre "el arte y la vida" se advierte que el arte surge desde la vida pero no se limita a plasmarla, ya que los contenidos abordados en la experiencia artística son: “...una función de la mente del hombre social y varía junto con ésta” ( p.61); por lo tanto, el arte se opone a lo real, apunta a otras realidades, completa la vida y amplía sus posibilidades, revela las contradicciones, surge de la insatisfacción en el vislumbre de otras alternativas y ayuda a la toma de conciencia de lo realmente sustantivo de la vida. La experiencia artística contribuye al enriquecimiento de la mente humana en tanto sus posibilidades de acción y representación, pero principalmente puede aportar al enriquecimiento de los sentimientos, pues el arte, según Vigostky, es una técnica social de los sentimientos y por tanto de gran valor educativo en la formación de un hombre nuevo, poseedor de una vida más plena y humanizada.

Frente a la trascendencia que Vigostky concede a la educación a través del arte, Jové (2002) se plantea el problema acerca de que lo medular del arte no puede ser enseñado, sólo los aspectos procedimentales pueden ser objetivados, mas no las sutilezas de los códigos artísticos en el orden sintáctico y semántico. Los procesos implicados en esta búsqueda son de orden inconsciente, y por ello no susceptibles de ser enseñables. Sin embargo, Vigostky deja abierto el camino cuando indica cómo a partir de la toma de conciencia es posible acceder a aquellos procesos, siendo lo esencial su desvelamiento, en cuanto acontece a la producción y apreciación de la obra artística.
De ahí la gran importancia de tener en cuenta una educación temprana, a través del arte, en el currículo escolar.

Entre líneas se puede entrever cómo el pensamiento de Vigostky sobre el arte y la Educación Artística se anticipa a las precisiones que sólo recientemente ha logrado el área, al ser reconocida en el currículo escolar como campo de saber estructurado con intencionalidades, objetivos y metodologías propias ${ }^{8}$. Lo anterior, implica que la Educación Artística se diferencia del arte, entendido como actividad profesional, no se propone formar artistas sino contribuir a la formación integral del educando. Desde este propósito, sin embargo, hay dos posturas diferenciadas: los enfoques esencialista y contextualista. El primero considera que el arte, por su naturaleza, es una experiencia vital que concilia las dimensiones humanas y posibilita la captación y el asombro de lo esencial de la vida, además de desarrollar aspectos de la sensibilidad humana como la agudeza perceptiva, la expresión creativa y la capacidad estético-valorativa. El segundo enfoque, desde una mirada de contexto, valora la experiencia artística desde su valor terapéutico, recreador y promotor de valores sociales y morales, básicos en la convivencia. $\mathrm{Al}$ respecto, se puede apreciar cómo Vigostky, el gran visionario, supo conciliar estas dos posturas concediendo a la Educación Artística un gran potencial formativo, siempre que el arte, como experiencia vital, se mantenga anclado a la cultura viva y esté presidido por valores auténticamente educativos.

Otros muchos son los aportes que puede representar la obra vygostkiana para la Educación Artística en la resignificación de las emociones, vista a la luz de sus conceptos de madurez. Veamos a continuación algunos de ellos:

\section{Sobre la experiencia del arte:}

-Los procesos artísticos confieren universos de significado y de sentido como procesos de interiorización de las emociones. 
-Las “ondas emocionales” que genera la expresión y apreciación artística, por cuanto se refieren a los problemas esenciales de la condición humana, logran penetrar en la sensibilidad para generar una catarsis, la fusión integradora de las emociones y los significados.

-En la experiencia artística se involucran todas las funciones psíquicas, trabajando de manera semiótica, usando herramientas que posibilitan emerger significados. En este recorrido, emparentado con lo sorprendente y lo sugerente, la conciencia ha de sentirse plena de disfrute.

-La vivencia del arte es un juego del espíritu, hace parte de la vida mental y de los procesos psíquicos de nivel superior, en cuanto interiorización de la herencia cultural.

Sobre el valor educativo de la experiencia artística:

- La educación a través del arte debe ser un pilar básico de la educación, en cuanto el arte educa para un mayor dominio de las capacidades vinculadas a la atribución de sentidos; aunque promueve el distanciamiento no ahuyenta lo emocional, pero aquí las emociones son de orden cortical y no meramente visceral.

- El arte tiene amplias posibilidades frente a la educación de la vida emocional, orientándola hacia el mundo de la sensibilidad inspirada por potenciadores sistemas de valores.

- El arte es una manera de pensar y de sentir dialécticamente, entonces ¿̇cómo no posibilitar que contribuya a la toma de conciencia en la reestructuración de las funciones psíquicas?

- Aunque lo más sustantivo del arte no puede ser enseñado de manera directa, sí las formas de vida artística y los procesos y modos de activación de la mente, mientras se produce arte o se disfruta de él. Por ello, los educadores pueden contribuir notablemente a que el arte tome vida en la mente de los escolares. El desafío estriba en ayudarlos a descubrir que su mente puede dar lugar a cierto tipo de significados, sentidos y emociones. En sentido estricto, los escolares pueden, mediante la Educación Artística, aprender a vivir momentos y circunstancias de manera artística. Naturalmente, estos sistemas de actividad deberán ser ajustados en función de sus niveles de desarrollo y aprendizaje.

-El aprendizaje del arte no puede ser mecanicista pero tampoco academicista. El arte sólo existe en las formas de vida insertas en el arte y por tanto, irreductibles a mero concepto; por otro lado, cada obra obedece a su propia germinación y no es producto de un recetario. Así los procedimientos, técnicas y materiales deben surgir de las exigencias de identidad de la obra.

Si bien el pensamiento pedagógico de Vigostky mira con simpatía el modelo pedagógico de la Escuela Activa, va más allá al trascender las propuestas de la auto-expresividad y del juego espontaneista ${ }^{9}$ de la educación progresista, cuando advierte cómo el potencial de la expresividad se agota, de no estar mediado por ricos procesos de culturización. Lo anterior implica que, más allá del cultivo de la expresión, se concede al docente gran protagonismo en la mediación cultural. Sus planteamientos sobre la zona de desarrollo próximo, con respecto al aprendizaje, tienen que ver con lo procesual de la interacción educativa y con las negociaciones continuas que se establecen en la mente de los participantes. Este desarrollo es dinámico y debe estar inmerso en la acción cargada de significados; sólo tiene existencia en cuanto las conciencias que interactúan comparten cierta actividad encaminada a potenciar el desarrollo de las funciones psíquicas y la asimilación cultural.

A juicio de Jové (2002), esta zona se constituye en un área de construcción del conocimiento. Por ello, la zona que se construya desde la Educación Artística ha de ser móvil y abierta, conllevar a actividades compartidas, próximas a las propias de las formas de vida de naturaleza artística y, en la pretensión de Vigostky, potenciar la vida mental y el enriquecimiento de todas las funciones psíquicas. La conciencia distanciada que opera a nivel metacognitivo aprende a leer el mundo de manera crítica e innovadora, y por ello, en la experiencia artística, posibilita desplegar 
visiones de mundo que, más allá de lo anecdótico, son capaces de dar vida a núcleos temáticos medulares de la condición humana.

Como se podrá apreciar en todo lo anteriormente expuesto, el pensamiento de Vigostky sobre el arte como educador de las emociones, desde una visión holística, resulta sumamente promisorio; significa el hallazgo de un pensamiento que por ser clásico no pierde vigencia, resultando hoy más actual que nunca; razones por las que se hace necesario integrarlo a las comprensiones recientes que han logrado que la Educación Artística hoy sea reconocida como un área fundamental del currículo escolar.

El papel del arte en el desarrollo del pensamiento ha ganado popularidad a partir del énfasis puesto por psicólogos cognitivitas como Gardner y Goodman, a raíz del proyecto Cero de Harvard y su proyecto derivado Arts Propel, que insiste en la importancia de la experiencia artística en la educación y su reconocimiento como un área que ha de tener en cuenta procesos específicos de desarrollo y formas consecuentes de aprendizaje y evaluación. Propel es consecuencia de las comprensiones logradas por Gardner (1995) acerca de la presencia de otros dominios de la inteligencia, diferentes del pensamiento lógico matemático y lingüístico, tales como la presencia de campos diferenciados en inteligencias musical, visual y cinético corporal. En el intento de medición de estos dominios del pensamiento, este autor se aproxima a la experiencia artística que los contiene de manera especial, y en ese encuentro observa que para evaluar, antes se requiere identificar cómo se da el aprendizaje artístico. En Educación artística y desarrollo humano Gardner (1994) destaca la contribución de Piaget a la comprensión del pensamiento pero le reclama no haber tenido en cuenta los valores culturales y las diferencias individuales. Sin embargo, ni él ni otros estudiosos actuales de la Educación Artística reparan en el gran Vigostky, que como bien dice Jové (2002), tal vez por su muerte prematura y por la dificultad de seguir su rastro en una obra suficientemente sistematizada ha tenido una mínima incidencia sobre la
Educación Artística. ${ }^{10}$ Su valoración de la experiencia artística contiene, al igual que en Gardner, el valor cognitivo, rebasándolo en cuanto su articulación con las emociones y en interacción con la cultura. De ahí su gran aporte a la Educación Artística como potencial formativo.

\section{BIBLIOGRAFÍA}

ElSTEr, J. (2001) Sobre las pasiones. Las Emociones Barcelona, Paidós.

FoRGAS, J. (2001) Handbook of affect social cognition.

GARDNER, Howard. (1995) Inteligencias múltiples: la teoría en la práctica. Barcelona, Paidós.

\section{Paidós.} (1994) Educación artística y Desarrollo Humano. Barcelona,

Jové Peres Juan J. (2000) Arte Psicología y Educación. Madrid, Machado libros. LOWENFEL V. y BRITAIN, (1980) L. Desarrollo de la Capacidad creadora. Buenos Aires, Kapeluz.

PIAGET, Jean (2001) Inteligencia y afectividad. Buenos Aires, Aique.

VIGOSTKY, Lev (2001). Psicología Pedagógica. La Educación de la conducta emocional. Buenos Aires, Aique.

----------- (2000) La imaginación y el arte en la infancia. Madrid, Akal. -- (1972) Psicología del Arte. Barcelona, Barral.

WARD, T., FINKE, R. y SMITH, S. (1995) Creativity and the mind. Discovering the genius within. Nueva York, Plenim Press.

NOTAS

1 Se recomienda consultar trabajos como los de: Forgas (2001) Handbook of affect and social cognition, Eich (2003) Cognición y emoción y Adolphs (2002) Emoción y conocimiento. Asimismo, las teorías mentalistas de Harris (1992) Los niños y las emociones.

2 Al identificar en la reacción emocional un mecanismo circular retroalimentador del campo propioceptivo, se entiende como un poderoso organizador interno de la conducta que da cuenta del carácter activo del sentimiento; esta función principalísima continúa hoy vigente y no puede ser desconocida.

3 Vygostky se refiere a cómo sentimientos egoístas son susceptibles de ser transformados en altruistas.

4 Como en el caso de las actividades artísticas que contienen un gran potencial lúdico $y$ afectivo.

5 Obra de transición muy cercana a la madurez del pensamiento de Vigostky.

6 Consultar las recientes investigaciones del grupo de investigación en cognición creativa de la Escuela de Texas Ward, T., Finke,R. y Smith, S. (1995) Creativity and the mind. Discovering the genius within. Nueva York, Plenim Press.

7 Los restantes capítulos están dedicados a pensar los diferentes campos artísticos y su desarrollo creativo en el ámbito escolar.

8 Las investigaciones de Elliot Eisner de la Universidad de Stanford sirvieron de base para la estructuración del área desde el reconocimiento de los procesos del aprendizaje artístico.

9 En la década de los sesenta, con Lowenfeld y Stern se sostuvieron posturas para la enseñanza del arte apoyadas en la libertad expresiva como fundamento de la creación artística.

10 Múltiples factores contribuyeron para que la obra vygostkiana hubiese permanecido ausente del pensamiento occidental, además de su muerte temprana a causa de una tuberculosis, los asuntos políticos tras el régimen Stalinista y quizá la dificultad del idioma. Por iniciativa de Jeronimus Bruner, uno de los más destacados psicólogos cognitivos, la obra de Vygostki fue traducida al inglés y luego conocida en el mundo entero, como una fuente de inspiración que logró integrar la subjetividad humana a una construcción cultural. 